\title{
Design of an Auxiliary Power Distribution Network for an Electric Vehicle
}

\author{
William Chen, Simon Round and Richard Duke \\ Department of Electrical \& Computer Engineering \\ University of Canterbury, Christchurch, NEW ZEALAND. \\ wwc14@student.canterbury.ac.nz
}

\begin{abstract}
This paper presents the design of an auxiliary power distribution network for an electric vehicle. Efficiency is a key element in the design for any electric vehicle and a $48 \mathrm{Vdc}$ distribution network will be used throughout the vehicle. The high efficiency Cuk converter has been selected as the most appropriate topology to supply the various distributed loads. To achieve the best compromise between efficiency and component sizes, a switching frequency of $100 \mathrm{kHz}$ is used. The results from simulations and experimental measurements are discussed and a range of proposals is also made to modify some of the existing loads to further improve efficiency.
\end{abstract}

\section{Introduction}

The University of Canterbury purchased a modern sports car "Toyota MR2" with the intention of converting it into an electric vehicle. This paper presents the design of the auxiliary power distribution network for the electric vehicle. In an electric vehicle, energy efficiency is extremely important and therefore the auxiliary power network must be designed for high efficiency. Another consideration is that due to the limited space and weight that can be carried in the vehicle, power supplies with minimal volume and weight are desired.

Current consumption investigations were made on the MR2's auxiliary loads. Transient current peaks occur when switching loads are switched in and out. These may load down the auxiliary converter and cause it to drop out, or shut down. In order to use the limited battery energy more efficiently, current limiting capability will be added to the converters to reduce the peak current demand. In addition, to improve efficiency, high intensity LEDs will replace the existing light bulbs in the vehicle.

The type of loads determines the power rating, number and placement of the auxiliary dc-dc converters that are connected to the auxiliary power distribution network in the vehicle. After initial investigations were conducted, the Cuk converter was selected as the most appropriate topology to supply the various distributed loads around the vehicle. This power supply is required to supply a
$12 \mathrm{Vdc}, 30 \mathrm{~A}$ output from a nominal $48 \mathrm{Vdc}$ input voltage.

To achieve a compromise between efficiency and component size, a switching frequency of $100 \mathrm{kHz}$ is used. The results from simulations and experimental measurements are discussed and a range of proposals is also made to modify some of the existing loads to further improve efficiency.

\section{Auxiliary system in the electric vehicle}

Figure 1 shows the auxiliary system that will be used in the electric vehicle. The nominal battery voltage of the electric vehicle will be $300 \mathrm{Vdc}$. To provide auxiliary supplies the voltage will be stepped down to $12 \mathrm{Vdc}$ in two stages with an intermediate $48 \mathrm{Vdc}$ distribution network.

The advantage of this configuration is that the $48 \mathrm{Vdc}$ voltage distribution network is more efficient than the usual $12 \mathrm{Vdc}$ distribution system. This is because with a higher voltage bus smaller and lighter wires are required to supply the same power to the auxiliary loads. A $300 \mathrm{Vdc}$ distribution network, although more efficient, was not considered an option because of safety issues.

\subsection{V Auxiliary load current requirements}

The power requirements of loads that are to be retained in the petrol-electric conversion need to be determined. The power rating was one of the factors that helped determine the type of dc-dc converters that will be used. Current consumption of loads is important for an electric vehicle as it determines the distance it can travel between recharging the batteries.

Transient current peaks occur in the measurements and they exist because loads are switched in and out. Figure 2 shows an example of measured hazard light current waveform. From the various current waveforms the peak and average currents were measured and tabulated for easy reference. Table 1 shows the summarised current consumption of the auxiliary loads in the vehicle. It is seen that the headlights, other external lights and power steering consume the major amount of power. Because of the limited energy stored in the supply batteries, efficient use of the power becomes the major concern in the design. 


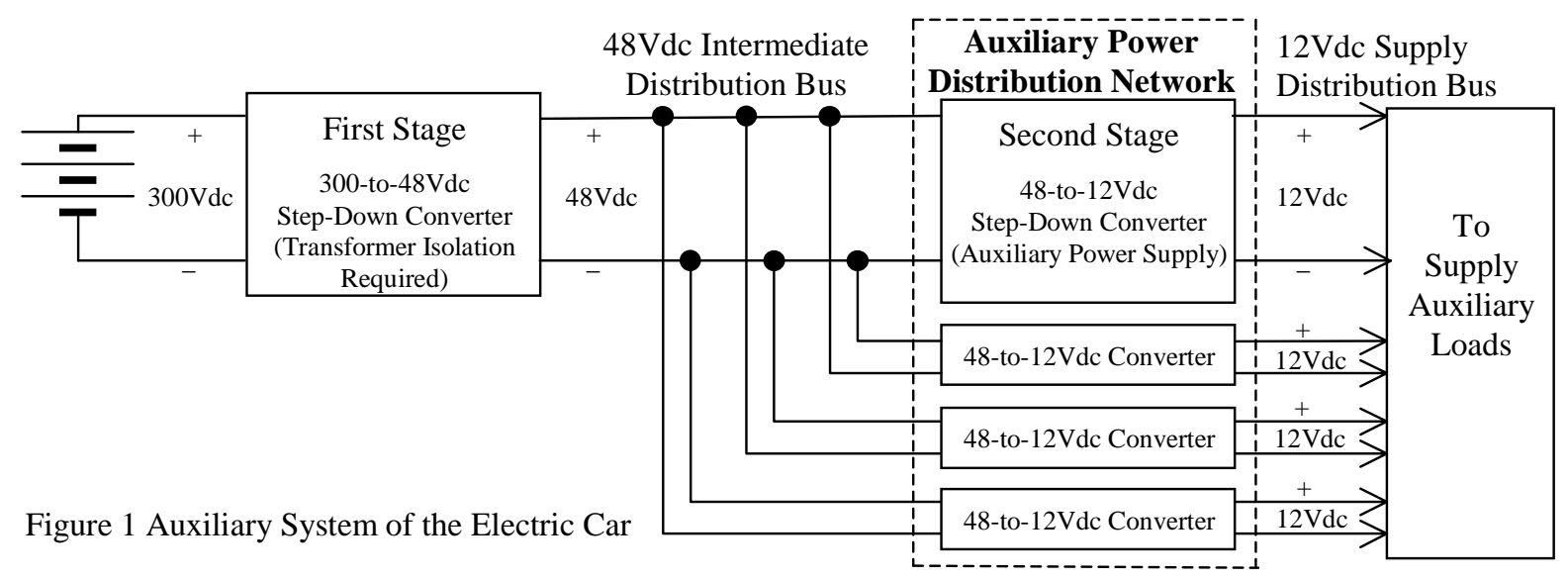

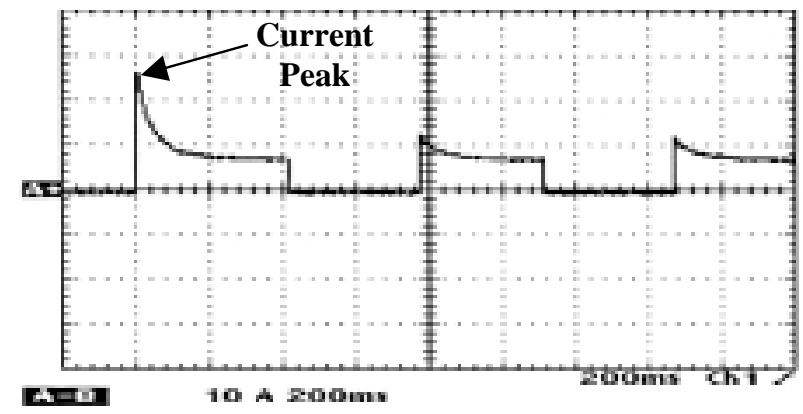

Figure 2 Current waveform of hazard lights

Current peaks must be reduced as they lead to a significant power loss in the system. In order to minimise the peaks, an experiment to check performance under current limiting conditions was undertaken on the loads. In the experiment, the auxiliary parts were tested under the condition of limiting the supply current to its average value and seeing whether it still functions the same. For example, power steering was tested using $25 \mathrm{~A}$ as the limiting current. The power steering operated successfully at this level since the peak current occurred only when the steering operates in hard lock. Therefore an output that limits the current to $25 \mathrm{~A}$ will be successful. All other auxiliary parts were found to operate properly in the current limit tests; thus, the power ratings of the converters are decided based on the average current values of the loads.

Another way of reducing power consumption in the car is to replace all the external and internal light bulbs in the vehicle, except headlights, with high intensity LEDs. Preliminary calculations that were carried out showed that current consumption of these loads decreased significantly if LEDs were used. For example, the current consumption of external lights would reduce from 31A (see Table 1) to $10 \mathrm{~A}$ by replacing all the external lights by LEDs.

\subsection{Power supply placement}

Using the information provided in Table 1 and assuming that the high intensity LEDs are used, a decision was
Table 1 Maximum Current Demand of the Loads

\begin{tabular}{|l|c|c|}
\hline \multirow{2}{*}{\multicolumn{1}{|c|}{ Loads }} & \multicolumn{2}{|c|}{ Maximum Current Consumed } \\
\cline { 2 - 3 } & $\begin{array}{c}\text { Peak } \\
\text { (Initial Spikes) }\end{array}$ & $\begin{array}{c}\text { Average } \\
\text { (Steady-State) }\end{array}$ \\
\hline Headlights & $27.4 \mathrm{~A}$ & $15 \mathrm{~A}$ \\
\hline External Lights & $53.8 \mathrm{~A}$ & $31 \mathrm{~A}$ \\
\hline Internal Lights & $10.3 \mathrm{~A}$ & $2.1 \mathrm{~A}$ \\
\hline Power Steering & $49.2 \mathrm{~A}$ & $25 \mathrm{~A}$ \\
\hline Fan, Heater & $25.6 \mathrm{~A}$ & $11.8 \mathrm{~A}$ \\
\hline All Other Electronics & $42.1 \mathrm{~A}$ & $20 \mathrm{~A}$ \\
\hline Total & $208.4 \mathrm{~A}$ & $104.9 \mathrm{~A}$ \\
\hline
\end{tabular}

taken to use four converters with output current ratings that range from 20 to $30 \mathrm{~A}$. Specifically, as the average current consumed in power steering is around $25 \mathrm{~A}$, one converter with a $30 \mathrm{~A}$ output will be placed beside it to supply the power. Another 30A power supply is going to be located in the front of the vehicle and supply the headlights and front external lights. A 20A converter will be placed behind the driver's seat to supply the internal lights and heater fans. Finally, the power of all other electronic equipments plus the external taillights is going to be supplied from a 30A power supply inside the boot of the vehicle. Figure 3 illustrates the placement of the four power supplies that will be used in the vehicle.

As an initial step in the project, a dc-dc converter with a 30A output current has been built and the design procedures are presented in the next section of this paper.

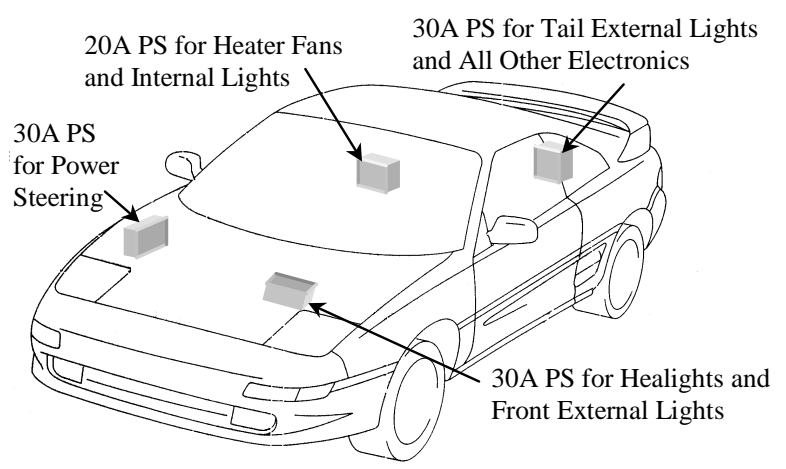

Figure 3 Power Supply Placements 


\section{Converter selection}

The Cuk converter topology was selected because it has both continuous input and output current with low current ripple Since the input and output inductor currents are essentially constant in steady state, the switching current is confined entirely within the converter, in the transistor-coupling capacitor-diode loop. With careful layout, this loop can be made physically small, which will reduce the radiated RFI. In addition, the voltage and current waveforms in this converter are particularly clean, with very little ringing or overshoot, and therefore very little snubbing is required [1,2]. Figure 4 illustrates the schematic Cuk converter.

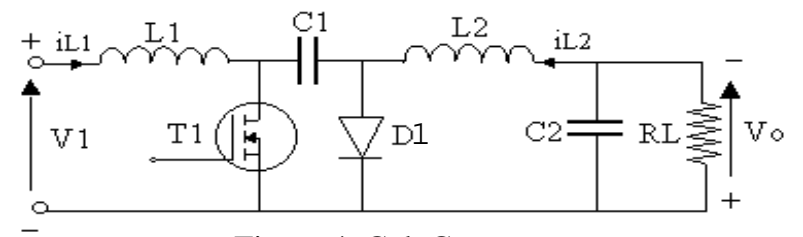

Figure 4. Cuk Converter

\section{Converter design}

\subsection{Design objectives}

The basic requirements of the Cuk converter are listed in Table 2. The normal functional voltage for auxiliaries in the vehicle is between $10.5 \mathrm{~V}$ to $14 \mathrm{Vdc}$. Therefore, the output voltage supplied from the converter is specified as $12 \mathrm{Vdc} \pm 10 \%$, which is inside the normal operational range of the auxiliary loads. In the auxiliary loads investigation carried out in Section 2.1, it was found that large current ripples occurred (between $1.3 \sim 4.2 \mathrm{Ap}$-p) while operating the auxiliaries; the output current is therefore specified as $30 \mathrm{~A} \pm 10 \%$.

\subsection{Component calculation}

The theoretical equations of [4] were used to calculate the component sizes using a switching frequency of $100 \mathrm{kHz}$. This switching frequency was selected because it provides a good compromise between efficiency and component sizes. Table 3 shows the calculation results.

\subsection{Converter simulation}

PSPICE is used to simulate the converter using the component values in Table3. The simulation was run until it reached steady state at a time of $9 \mathrm{~ms}$. Figure 5 shows the voltage and current waveforms generated from the simulations for two switching periods. Voltage ripple of $140 \mathrm{mVp}-\mathrm{p}(2 \%)$ is obtained at the output of the converter as shown in Figure 5(a).
Table 2 Basic Requirements

\begin{tabular}{|l|l|}
\hline Input Voltage & $48 \mathrm{Vdc}$ \\
\hline Output Voltage & $12 \mathrm{Vdc} \pm 10 \%$ \\
\hline Output Current & $30 \mathrm{~A} \pm 10 \%$ \\
\hline $\begin{array}{l}\text { Maximum Output Voltage } \\
\text { Ripple }\end{array}$ & $\begin{array}{l}1.2 \mathrm{~V} \text { peak-to-peak } \\
(<10 \% \text { of } 12 \mathrm{~V})\end{array}$ \\
\hline $\begin{array}{l}\text { Maximum Current Ripple of } \\
\text { Inductance L2 }\end{array}$ & $\begin{array}{l}\text { 3A peak-to-peak } \\
\text { (<10\% of 30A) }\end{array}$ \\
\hline Minimum Efficiency & Preferably > 85\% \\
\hline Input Protection & Over voltage \\
\hline Output Protection & $\begin{array}{l}\text { Over voltage, Over } \\
\text { current, Short circuit }\end{array}$ \\
\hline
\end{tabular}

Table 3 Calculation Results

\begin{tabular}{|c|c|}
\hline Duty Ratio, D & $33 \%$ \\
\hline Inductance, L1 & $211.2 \mu \mathrm{H}$ \\
L2 & $52.8 \mu \mathrm{H}$ \\
\hline Capacitance, C1 & $33 \mu \mathrm{F}$ \\
\hline C2 & $15.86 \mu \mathrm{F}$ \\
\hline Load & $0.4 \Omega$ \\
\hline
\end{tabular}

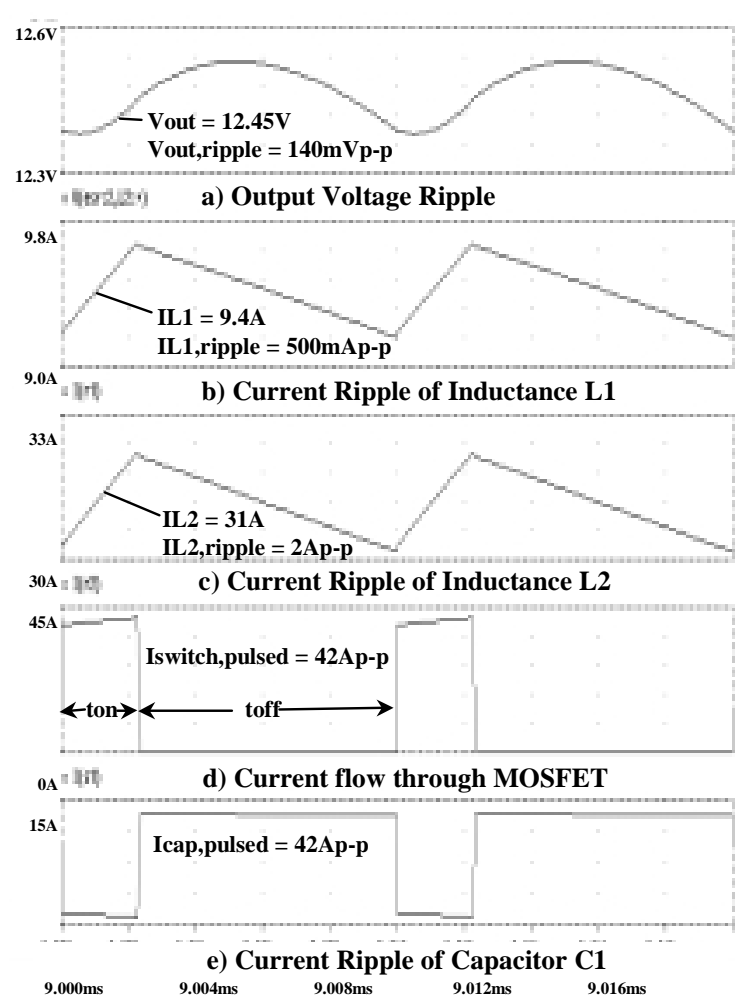

Figure 5. Simulated waveform of the Cuk converter.

Figures 5(b) and (c) show the inductor L1 and L2 current waveforms respectively. In inductor L2 the current ripple is 2Ap-p (6.7\%).Large amount of pulsed current, 42Ap-p, flows through the switch and capacitor $\mathrm{C} 1$ on each PWM cycle as shown in Figure 5(d) and (e) respectively. 


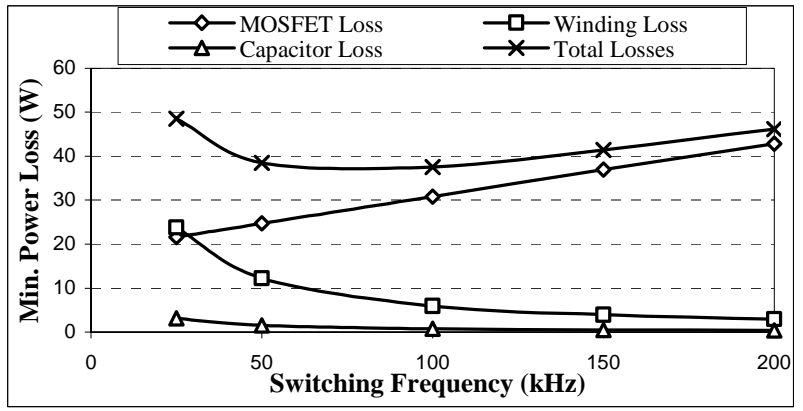

Figure 6 Estimated Cuk Converter Component Loss

\subsection{Circuit losses estimation}

At various switching frequencies theoretical calculations were made to determine the component values and their losses [4]. Figure 6 illustrates the estimated component losses of the converter over a range of switching frequencies. MOSFET losses were estimated by adding the magnitude of conduction and switching loss in the switch. The power losses in the passive components were determined by finding the product of their series resistance and the current flowing through them. Using the information provided in Figure 6, PSPICE simulations were carried out to determine the overall efficiency of the converter over a range of switching frequencies as shown in Figure 7

\subsection{Switching frequency selection}

The need for a high efficiency converter dictates a careful selection of switching frequency. This in turn has an impact on the size of the passive components. Using Figures 6 and 7 a choice of $100 \mathrm{kHz}$ as the switching frequency was made. This choice is a compromise between choosing high efficiency and small components.

\subsection{Inductor design}

The basic inductor design procedure of Billings was followed [5]. Using the ripple current values given in Figure 5(b) and (c), the input parameters of the inductance design are determined and listed in the Table 4. Inductors L1 and L2 are wound on ETD49 and ETD59 ferrite core respectively. Theoretical calculations were carried out and found that without a air-gap, both inductor cores would be saturated at the $100 \mathrm{kHz}$ switching frequency.

Table 4 Input Parameters of Inductance Design

\begin{tabular}{|l|l|l|}
\hline Inductor & $\mathrm{L} 1$ & $\mathrm{~L} 2$ \\
\hline Inductance & $211.2 \mathrm{uH}$ & $52.8 \mathrm{uH}$ \\
\hline Peak Current & $9.6 \mathrm{~A}$ & $32 \mathrm{~A}$ \\
\hline DC Current & $9.4 \mathrm{~A}$ & $31 \mathrm{~A}$ \\
\hline Max. Temp. & $100^{\circ} \mathrm{C}$ & $100^{\circ} \mathrm{C}$ \\
\hline
\end{tabular}

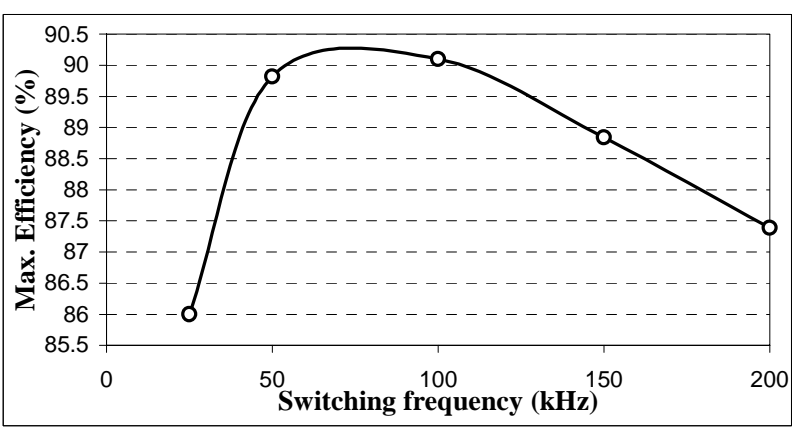

Figure 7 Simulated Cuk Converter Efficiency

Therefore an air-gap must be added in these cores to reduce magnetic flux density. However, the result is that extra windings are needed to regain the required inductance. To achieve the best compromise between the core size and the copper loss, an air-gap of $3 \mathrm{~mm}$ was selected for both cores. This was verified from the tables and figures provided in the Philips Soft Ferrite data book [6].

\subsection{Component selections}

In the Cuk converter topology, all the current transferred from input to output must pass through capacitor $\mathrm{C} 1$. The converter delivers high currents and this results in an enormous ripple current flowing through the capacitance $\mathrm{C} 1$ during each PWM period. This is confirmed by PSPICE simulation as shown in Figure 5(e). Due to a large ripple current of up to 40Ap-p, electrolytic capacitors are not considered suitable. Plastic Film type MKT capacitors are used since they offer high AC stress properties. $\mathrm{C} 1$ is constructed from ten $3.3 \mu \mathrm{F}$ capacitors connected in parallel. The capacitors that form the output filter must also be able to handle an appreciable amount of ripple current of up to 3Ap-p. To handle this ripple current, ten $47 \mu \mathrm{F}$ electrolytic capacitors were connected in parallel to form the output capacitor $\mathrm{C} 2$.

To maximize the efficiency of the converter, the switch was chosen to have low conduction and switching losses. An Intersil RFP40N10 N-channel MOSFET was selected to provide higher than necessary current and voltage ratings with low $\mathrm{R}_{\mathrm{DS},(\mathrm{ON})}$ of $0.04 \Omega$ and fast on and off switching times (47ns and 62ns respectively).

Since the converter is used in a step-down application, a high forward-voltage drop in the diode will result in an enormous power loss in the converter. An International Rectifier 30CPQ100 high efficiency, schottky diode was chosen as it offers a low forward-voltage drop of $0.86 \mathrm{~V}$ and has the capability of handling large current and reverse blocking voltage of $30 \mathrm{~A}$ and $100 \mathrm{~V}$ respectively. 


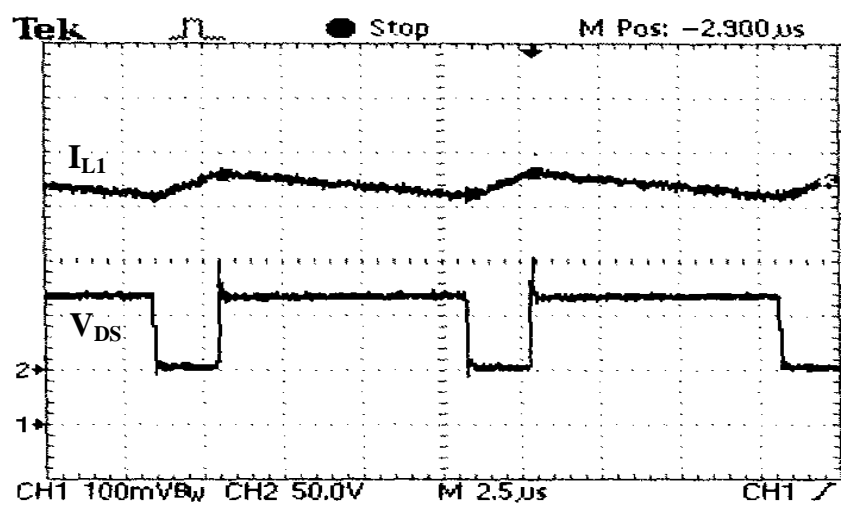

Figure 8 Input inductor current ripple (Top, 2A/div), and MOSFET switch voltage waveform (Bottom, 50V/div). Time scale: $2.5 \mu \mathrm{s} / \mathrm{div}$

\section{Prototype performance}

The prototype model of the $12 \mathrm{~V}, 30 \mathrm{~A}$ converter has been built and tested for efficiency and steady state output voltage ripple. Under full load, the average current flowing through the Schottky diode is 30A. The diode's forward voltage drop of $0.86 \mathrm{~V}$ limits the converter's theoretical maximum efficiency to $93.3 \%$.

The measured efficiency of the switching converter at various loads is listed in Table 5. Under nominal operating conditions of $48 \mathrm{~V}$ input, $30 \mathrm{~A}$ output, the efficiency is measured to be $85.2 \%$. The highest efficiency of $92.4 \%$ was obtained at $2 / 3$ load (20A). The characteristic switching waveforms of Figure 8 and 9 show reasonably clean switching under the full load condition and confirms the correct operation of the converter.

Table 5. Measured Efficiency of the Converter

\begin{tabular}{|c|c|c|c|c|c|}
\hline $\begin{array}{l}\text { Load } \\
\text { Condition }\end{array}$ & $\begin{array}{l}\text { Vin } \\
\text { (V) }\end{array}$ & $\begin{array}{l}\text { Iin } \\
\text { (A) }\end{array}$ & $\begin{array}{l}\text { Vout } \\
\text { (V) }\end{array}$ & $\begin{array}{l}\text { Iout } \\
\text { (A) }\end{array}$ & $\begin{array}{c}\text { Effi. } \zeta \\
(\%)\end{array}$ \\
\hline 1/3 Load & 48.2 & 2.8 & 12.0 & 10.0 & 89.0 \\
\hline 2/3 Load & 48.1 & 5.4 & 12.0 & 20.0 & 92.4 \\
\hline Full Load & 48.0 & 8.8 & 12.0 & 30.0 & 85.2 \\
\hline
\end{tabular}

Ideally, the nominal voltage across the power devices (MOSFET and Diode) is 60Vp-p. As seen in the Figures 8 and 9 , voltage spikes occur when the switches are turned on or off. Voltage clamps (RCD Snubbers) are designed and implemented across these power devices to reduce the voltage spikes and to limit the overall peak-to-peak voltage. Consequently, the voltage across the power devices is $95 \mathrm{Vp}$ - $\mathrm{p}$ and $92 \mathrm{Vp}$-p respectively when using the voltage clamps. The current ripple of inductor L1 and the output voltage ripple are measured as $514 \mathrm{mAp}-\mathrm{p}$ and $212 \mathrm{mVp}$-p respectively. These values are close to the simulation results of 500mAp-p and $140 \mathrm{mVp}$-p as given in Section 4.3. The measured output voltage is $12 \mathrm{~V} \pm 5 \%$, which is within the specification of $\pm 10 \%$.

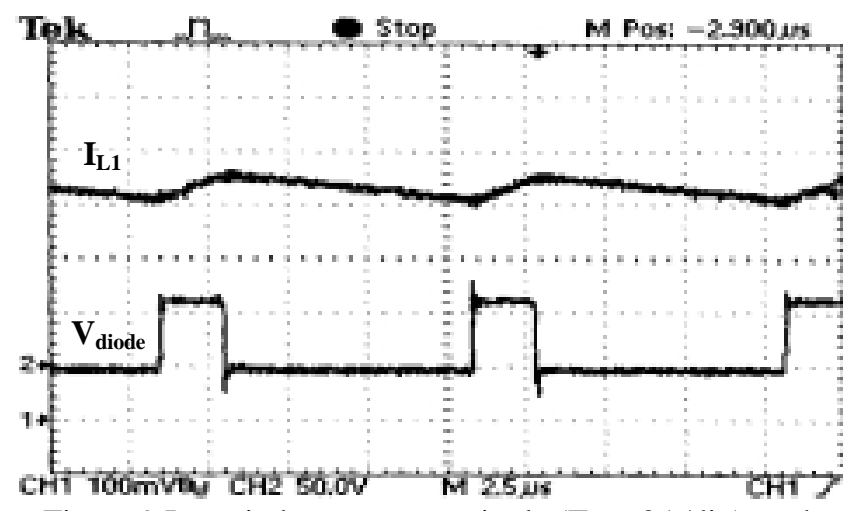

Figure 9 Input inductor current ripple (Top, 2A/div), and Diode switch voltage waveform (Bottom, 50V/div). Time scale: $2.5 \mu \mathrm{s} / \mathrm{div}$

\section{Conclusions}

A distributed power network is to be used in an electric vehicle application. The $300 \mathrm{Vdc}$ nominal battery voltage is converted to $48 \mathrm{~V}$ intermediate voltage. The use of high efficiency LEDs and power supply current limiting results in reduced energy consumption by the auxiliary loads. A Cuk converter has been designed and implemented that converts $48 \mathrm{~V}$ to $12 \mathrm{~V}$ at a maximum load current of $30 \mathrm{~A}$. The converter operates at $100 \mathrm{kHz}$ and has a maximum efficiency of $92.4 \%$ at $2 / 3 \mathrm{load}$. Comparison between waveforms captured from the prototype and simulation results are similar. This indicates that the simulation results are a good predictor for the experimental results.

\section{References}

[1] T. S. Finnegan, "Cuk: the best SMPS?", Electronics World + Wireless World, January 1991, pp 69-72

[2] S. Cuk and R.D. Middlebrook, "A New Optimum Topology Switching dc-to-dc Converter", IEEE Power Electronics Specialist Conference 1977 pp 160-179

[3] Zhe Zhange and S. Cuk, "A High efficiency 1.8kW Battery Equalizer" Applied Power Electronics Conference, 1993 Record, pp.221-227.

[4] Daniel W. Hart, An Introduction to Power Electronics, Upper Saddle River, N.J. : Prentice Hall, c1997, pp.205-201.

[5] Keith Billings, Switch Mode Power Supply Handbook, $2^{\text {nd }}$ Ed, McGraw-Hill, Inc, c1999, pp.3.33.28 .

[6] Philips Soft Ferrites Data Book 1998.

[7] Zhe Zhange and S.Cuk, "A High Efficiency 500W Step-up Cuk Converter" Applied Power Electronics Conference, 199 Record, pp.909-914. 